\title{
Bridging Classroom to Experiential Learning: A Review of Signature Pedagogies in Two Disciplines
}

\author{
Beck, V.* and King, K.** \\ *Department of Criminal Justice.University of Wisconsin Oshkosh \\ 316 Halsey South.Oshkosh, WI 54901-865 (United States) \\ beckv@uwosh.edu \\ **Public Administration Program.University of Wisconsin Oshkosh \\ 320 Halsey South. Oshkosh, WI 54901 (United States) \\ kingk@uwosh.edu
}

\begin{abstract}
The focus of this review is to promote and advance discussions on the importance of applied learning techniques in bridging the gap between the classroom and the real world experiences, by reviewing the empirically identified benefits and limitations of two signature pedagogies. The authors conclude that it may be advantageous to develop a set of shared standards flowing from lessons learned in the application of applied learning approaches across the curriculum. The authors also suggest students should be encouraged to participate in experiential education to liberate their thinking and gain practical work experience.
\end{abstract}

Keywords: Applied learning; experiential learning; case studies; internships; public administration; criminal justice.

\section{Introduction}

To become competent public servants, students must understand the theories and best practices in their discipline, as well as how to apply that information. To help students make connections between the classroom and real world experiences, some disciplines have adopted specific teaching pedagogies to organize "the fundamental ways in which future practitioners are educated for their chosen professions" (Shulman, 2005, p. 52). While these "signature" pedagogies have proven to be valuable resources, they are not necessarily the exclusive domain nor used solely by a particular discipline. In this paper, scholars from public administration and criminal justice share signature pedagogies used to provide a bridge between classroom learning and the real world of public service.

\section{Case Studies in Public Administration}

Educators in the discipline of public administration use a wide variety of instructional techniques to help students take what they have learned in class and apply it to the world of public service and one such technique is the case study. While the move toward using the case study approach for training pre-professional students in public administration classes emerged in the mid-1930s, it originated with the Harvard Law School around 1870 (Lynn, 1999). Viewing the approach in an abstract sense, Stein (1952) defined a case study as an "examination of the particulars prior to or as part of a generalization” (pp. xx-xxi). More specifically, however, Lynn (1999) describes a teaching case as "a story, describing or based on actual events and circumstances, that is told with a definite teaching purpose in mind and that rewards careful study and analysis” (p.124). Lynn (1999) identifies three characteristics of a case study: it furthers the development of professional intellectual and behavioral skills; it is issueor problem-oriented; and it is essentially concerned with interpreting real-world experience (p. 3). Brooks, Harris and Clayton (2010), referencing Desanto-Madeya, conclude that "case-based pedagogy is a creative learning strategy that not only 
enhances critical thinking and problem-solving but also decision-making skills” (p. 55).

Public administration policy case studies come in all sizes and are used to accomplish a variety of pedagogical purposes. Cases, sometimes as short as one page and dealing with a very specific set of circumstances, can be used to stimulate class or small group discussions that are related to a specific unit within a larger subject for examination. For example, PA TIMES, the newsletter of the American Society for Public Administration (ASPA), regularly prints a column titled “An Ethics Moment” which incorporates brief case studies on ethics in a public service setting for classroom use. Case studies that focus on more complex political or economic questions can be studied over the course of a semester and, if appropriate, presented as a group project at the end. For example, a discussion of the concept of "Budgeting as a Political Choice" can be linked with a state's budget deficit.

\section{The benefits of the case study method}

Public administration instructors use the case study method extensively because it has the ability to prepare "learners for a world that demands critical thinking skill and the ability to create convincing arguments, often with little time and incomplete information" (Lynn, 1999, p. 2). While managerial situations are often unique, certain types (i.e., disciplining employees) tend to appear on such a regular basis that studying cases about them in class does present an approximation of the world of public service that is not possible from reading a textbook account (Golembiewski \& Stevenson, 1998). Further, some case studies, especially the longer more complicated ones, can be written in such a way as to challenge readers to delve further into the subject

The most common use of case studies in a classroom setting is for students to react to prepared cases in public policy and administration supplied by their instructor. However, writing assignments can require students to discuss their actual experiences in an organizational setting, which helps students to analyze a workplace problem by organizing issues in a logical manner, presenting interesting narrative, and developing compelling questions that expanded the participants' understanding of the case.

The limitations of the case study method

While the case study method is a versatile teaching strategy, challenges have been noted. For example, not all case studies are well-written or easily implemented, even when written by experts and/or appearing in textbooks. Also, case studies can sometimes appear overly theoretical or unrealistic. Further, the questions that are supposed to help students connect the circumstances of the case study to broader issues and practices in public administration may fail to do so.

Students sometimes express frustration with case studies. The fact that the ultimate outcome of a case might not be known perturbs some. Students also complain that there is not enough information for them to undertake a comprehensive analysis of the case, or make a logical recommendation for action. Of course, it is appropriate at this point to remind students that the kinds of situations they will encounter as government workers are typically characterized by insufficient information, inadequate time, and lack of follow-up, which is why it is important to practice critical thinking skills in class by engaging with real cases. 
Despite the above noted limitations, case studies provide a focus on the application of classroom activities to situations that public administrators might encounter in the field. Consequently, the case study teaching method is an excellent resource for instructors whose students are the government workers of the future.

\section{Internships in Criminal Justice}

In many disciplines, the integration of theory into experiential learning is an essential part of education (Ciofalo, 1992; Parilla \& Smith-Cunnien, 1997; Reed \& Carawan, 1999), and one way to achieve such integration is through the use of internships. The variety of internship opportunities in criminal justice is almost boundless and perhaps limited only by a student's ability to: find time to participate; grade point average, since some programs require a specific GPA for interns; and prior criminal record, as most social agencies run a criminal background check on interns.

Although the use of internships dates back to medieval times (Ross \& Elechi, 2002), it is a controversial pedagogy (Stone \&McLaren, 1999). The core of the debate surrounding the use of internships focuses on the purpose of a university education. "Academic purists view the university as a place where people are taught to think" (Stone \& McLaren, 1999, p. 171) and are concerned that internships will not contain sufficient academic content (Sgroi \& Ryniker, 2002), while professionally oriented academic programs endorse internships and potential employers believe universities should help prepare young people for employment (Stone \& McLaren, 1999). Historically, the debate on the use of internships in academics has, perhaps, been more common in criminal justice, as a discipline struggling to attain legitimacy as a social science rather than as a "cop shop" (Durham, 1992). Consequently, not all criminal justice programs include internships.

\section{The benefits of internships in criminal justice}

Despite the debates surrounding the pedagogical use of internships, research on criminal justice internships have noted a variety of pedagogical and social benefits. In addition to having the opportunity to apply classroom learning to real world experiences, internships assist students in: building social relationships and interacting with diverse populations; determining how to respond to challenging situations; improving problem solving and communication skills; improving the ability to make appropriate career decisions and transitioning from school to work (Stichman and Farkas, 2005).

Community agencies also benefit from the use of internships in academic programs. In the discipline of criminal justice, specifically, community agencies benefit when: interns provide current skills and knowledge that may encourage updates to agency practices; interns energize agency staff and help promote agency image; and interns provide temporary qualified workers at little to no cost (Stichman and Farkas, 2005). The benefits for academic programs include: enhanced knowledge of agency needs and issues in the field, which can inform teaching; and improved student retention (Stichman and Farkas, 2005).

\section{The limitations of internships in criminal justice}

While it is clear that criminal justice internships provide reciprocally beneficial relationships between student, community and the academic program, there are noted limitations. According to Stichman and Farkas (2005) internships: may not always 
promote integration of theory with practice; may be viewed as an easy way to improve GPA; may result in anecdotal application of information; may create legal liability; may result in students being assigned to menial tasks unrelated to learning. Other limitations may include lack of a faculty or student handbook delineating clear guidelines and policies for the internship; lack of time and resources for faculty supervisors to review and assess agencies and students; and lack of compensation, which may prevent working students from participating (Stichman and Farkas, 2005).

Internships have been and continue to be a prominent pedagogy in criminal justice programs (Reed \& Carawan, 1999), as well as other programs such as psychology and sociology. Indeed, based on data from National Survey of Student Engagement, Kuh (2008) found internships to be one of the "high impact" educational experiences that increase rates of student retention and engagement. The results in Kuh (2008) have led to a set of suggested standards to improve the quality of the internship experience, across disciplines: internships should be effortful (commitment to task); help students build substantive relationships with faculty, staff and/or co-workers; help students experience diversity and new ways of thinking; provide rich feedback; promote integration and application of knowledge; and provide opportunities for students to reflect on the person they are becoming (see also discussion of Kuh, 2008 in O'Neil, 2010). Unfortunately, it is not known to what extent these suggested standards have been widely adopted, nor does there appear to be research on the effectiveness of these suggested standards. Nonetheless, the Council for Advancement of Standards in Higher Education and Kuh (2008) do provide a framework to begin the discussion on standardizing definitions of and practices in internships to ensure a consistent and quality experience for students, across disciplines.

\section{Conclusions}

Applied learning courses vary widely and continue to proliferate in universities across the U.S. Nonetheless, curricular standards associated with experiential learning techniques have developed independently and with little interaction among advocates (Freeland, 2009 p. 9). This lack of interaction, even among those who believe in their value, leaves applied learning techniques open to criticism that such approaches can be merely career oriented, which does not fit within the tenets of a liberal arts degree. Perhaps one of the ways to curtail criticism of applied learning as being simply "career oriented" is to develop a set of shared standards, which flow from lessons learned in the application of applied learning approaches across the curriculum.

The preceding sections provide practical guidelines for exploring pedagogies bridging classroom learning to real world experiences. While each discipline may have a signature pedagogy to building a bridge, all can benefit from observing the best practices of their colleagues in other fields of study. The information discussed herein also suggests that students should be encouraged to participate in experiential education to liberate their thinking and gain practical work experience, which may result in graduating students who reflect the importance of a well-rounded education and who are well prepared to succeed in their careers and lives. 


\section{References}

Brooks, E., Harris, C.R. and Clayton, P. H. (2010). Deepening applied learning: An enhanced case study approach using critical reflection. Journal of Applied Learning in Higher Education, 2, 55-76.

Ciofalo, A. (1992). What every professor and work-site supervisor should know about internships. In A. Ciofalo (ed.), Internships: Perspectives on experiential learning (pp. 3-7). Malabar, FL: Krieger.

Freeland, R. M. (2009). Liberal education and effective practice: The necessary revolution in undergraduate education. Liberal Education, 95(1), 6-13.

Golembiewski, R. T. \& Stevenson, J. G. (1998). Cases and applications in nonprofit management. Itasca, IL: F.E. Peacock Publishers, Inc.

Kuh, G.D. (2008). High-impact educational practices: What they are, who has access to them, and why they matter. Washington, DC: Association of American Colleges and Universities. www.neasc.org/downloads/aacu_high_impact_2008_final.pdf

Lynn, Jr. L. E. (1999). Teaching and learning with cases: A guidebook. New York, NY: Chatham House Publishers.

O’Neill, N. (2010). Internships as a high-impact practice: Some reflections on quality. Peer Review 12(4), 4-8.

Parilla, P.F. \& Smith-Cunien, S.L. (1997). Criminal justice internships: Integrating the academic with the experiential. Journal of Criminal Justice Education 8(2), 225-242.

Reed, J.G. \& Carawan, .W. (1999). Beyond sibling rivalry: Criminal justice internship on a social work model. Journal of Criminal Justice Education 10(1), 153-170.

Ross, L.E. \& Elechhi, O.O. (2002). Student attitudes towards internship experiences: From theory to practice. Journal of Criminal Justice Education 13(2), 297-312.

Sgroi, C.A. \& Ryniker, M. (2002). Preparing for the real world: A prelude to a fieldwork experience. Journal of Criminal Justice Education 13(1), 187-200.

Shulman, L. (2004). Teaching as a community property: Essays on higher education (JB-Carnegie Foundation for the Advancement of Teaching). San Francisco, CA: Jossey-Bass Publishers.

Stein, H. (1952). Case method and the analysis of public administration. In Public administration and policy development: A case book. New York: Harcourt, Brace and Co.

Stone, W.E. \& McLaren, J. (1999). Assessing the undergraduate intern experience. Journal of Criminal Justice Education 10(1), 171-183. 